\title{
SANTIAGO DE CHILE, GLOBALIZACIÓN Y EXPANSIÓN METROPOLITANA lo que existía sigue existiendo
}

\author{
Carlos A. de Mattos \\ Instituto de Estudios Urbanos, Pontificia Universidad Católica de Chile
}

\begin{abstract}
Resumen: La profunda reestructuración iniciada en Chile con la aplicación de una radical estrategia de liberalización económica a mediados de los 70's, culminó una década más tarde en una etapa de sostenido crecimiento económico, reindustrialización y terciarización. En ese proceso, tanto el comando del nuevo poder económico, como las principales actividades industriales y terciarias mostraron una clara preferencia por localizarse en el Area Metropolitana de Santiago (AMS), intensificando nuevamente tendencia a la concentración territorial. Se ha consolidado así una ciudad-región, suburbanizada y policéntrica, de límites imprecisos, configurada como archipiélago.

Palabras clave: metropolización; periurbanización; suburbanización; segregación urbana.
\end{abstract}

Hablar de reproducción es mostrar los procesos que permiten que lo que existe siga existiendo. En un sistema en que las relaciones internas se transforman, no todo sigue existiendo. Es necesario, por lo tanto, estudiar el modo en que surge lo nuevo en el sistema.

Michel Aglietta, 1979:4

$\mathrm{H}$ acia comienzos de la década de los años 70 , luego de haber estado vigente por más de cuatro décadas, el modelo de crecimiento hacia adentro vía industrialización sustitutiva, que había sido impulsado en Chile mediante una activa intervención estatal, comenzó a mostrar síntomas claros de haber llegado a una fase de agotamiento sin retorno. En esas circunstancias, a medida que día a día se acentuaba una conflictividad social incubada durante largos años, se fue generando un ambiente propicio para el despliegue de algunas respuestas alternativas que, cuando menos en el plano verbal, ponían en cuestión la propia continuidad del derrotero capitalista seguido por el país hasta ese momento. Fue entonces cuando pudo percibirse una creciente receptividad y apoyo social, tanto hacia un discurso que preconizaba que la salida debía buscarse siguiendo una "vía no capitalista de desarrollo", como hacia otro que alegaba que ello podría lograrse mediante una "transición democrática al socialismo".

\section{CRISIS, MODERNIZACION, REPRODUCCION}

El intento de poner en marcha la segunda de estas opciones, contribuyó decisivamente a hacer incontrolable la evolución de la crisis del modelo de industrialización sustitutiva $y$, en consecuencia, a abrir las puertas a una radical reestructuración productiva, con la que se inició un nuevo período modernizador estricto sensu capitalista en Chile. Quienes habían venido promoviendo desde mediados de los años 70 la implantación de una drástica política de liberalización económica, sostenían que este era el camino idóneo para "lograr una economía descentralizada" que permitiría "utilizar los recursos con que cuenta el país a su máximo nivel de eficiencia, para alcanzar así tasas aceleradas de desarrollo que permitan, no sólo elevar la condición media de vida de los chilenos, sino también erradicar del país las condiciones de extrema miseria en que vive un sector importante de la población" (De Castro, 1992:16).

Al mismo tiempo, también anticipaban que, por esta vía, sería posible llegar a una distribución territorial más equilibrada de las actividades productivas y de la población. Con un fundamento teórico de corte neoclásico sobre crecimiento, equilibrio y convergencia interregional, las previsiones respectivas afirmaban su convicción de que “(...) la nueva perspectiva de la economía nacional permite esperar el desarrollo de un sistema urbano más equi- 
librado, orientado principalmente al aprovechamiento de las ventajas comparativas que ofrece la distribución territorial de los recursos naturales y la apertura hacia un amplio mercado mundial" (MINVU, 1981:11).

Más allá de los cambios políticos ocurridos desde el inicio de su aplicación, los criterios básicos que sustentaban esta nueva estrategia (economía de libre mercado, Estado neutral y subsidiario, amplia apertura externa) han permanecido vigentes en Chile por más de dos décadas. Si bien tanto las políticas aplicadas para enfrentar la depresión que afectó duramente a la economía chilena entre 198283, como las correcciones realizadas a partir de 1990 con el retorno a la democracia, tuvieron un mayor componente regulatorio que las aplicadas inicialmente, esto no significó introducir ninguna modificación sustantiva a aquellos criterios básicos.

Esta permanencia permite considerar las transformaciones que han afectado a Santiago, y, a su área metropolitana, como ejemplos de los efectos que la dinámica socio-económica de la reestructuración y la globalización puede tener sobre una metrópoli periférica $\mathrm{y}$, al mismo tiempo, plantear la discusión sobre si lo que se ha estado produciendo es un tipo diferente de configuración urbana o una profundización y/o culminación de tendencias ya perceptibles en el período de apogeo de la industrialización sustitutiva; en otras palabras, si las transformaciones producidas, bajo los efectos de la reestructuración y la globalización, corresponden a una ruptura con la ciudad heredada, o a la reproducción de un tipo de configuración metropolitana en el que, para decirlo con las palabras de Aglietta, en lo fundamental, "lo que existía sigue existiendo". Como lo indica el título del trabajo, el análisis que aquí se realiza busca aportar elementos de juicio en favor de esta segunda interpretación.

Con este propósito, observaremos las transformaciones que han afectado al Area Metropolitana de Santiago $\left(\mathrm{AMS}^{1}\right)$ durante el período de sostenido y elevado crecimiento económico vivido entre los años 1985 y $1998^{2}$ bajo los efectos de la reestructuración y de la globalización. En lo fundamental, luego de esbozar algunos aspectos de las transformaciones experimentadas por la economía chilena en el período indicado, analizaremos sus efectos en la formación de una nueva base económica metropolitana, en las tendencias locacionales de las principales actividades que la conforman, y, en la consecuente recuperación del crecimiento metropolitano. A partir de allí, y, teniendo presente las consecuencias de las políticas de liberalización y de desregulación que signaron a la gestión urbana en este período, se caracterizarán los cambios que se observan en tres dimensiones de la metrópoli emergente (Esquema 1): en primer lugar, en la modalidad de expansión metropolitana y, por consiguiente, en la morfología resultante de la metrópoli (efectos morfológico-territoriales); en segundo lugar, en la organización y situación social de la aglomeración (efectos socio-territoriales); y, en tercer y último término, en la estructura física de la metrópoli, como consecuencia de los impactos provocados por un conjunto de nuevos artefactos urbanos cuya irrupción puede asociarse a los avances de la globalización (efectos físico-territoriales).

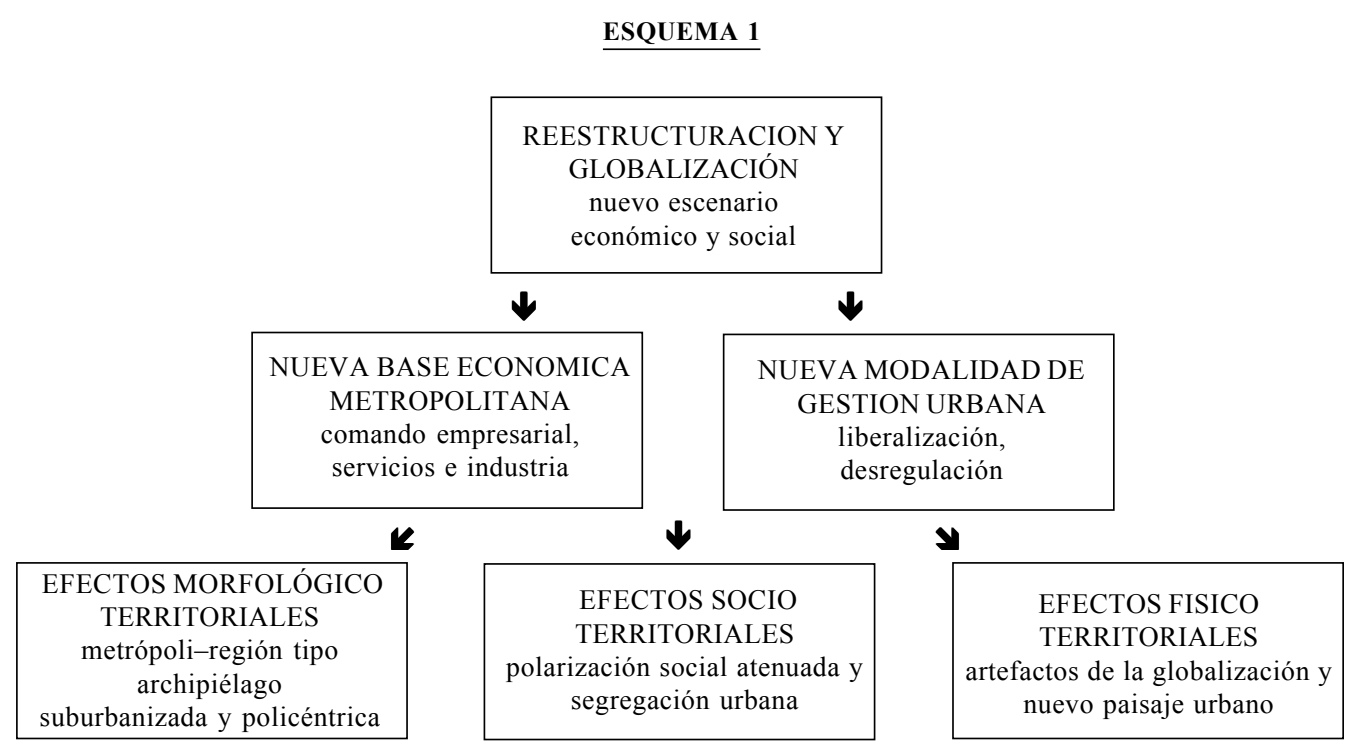




\section{EL NUEVO ESCENARIO ECONOMICO Y SOCIAL}

\section{Reestructuración y Transformaciones Económicas y Sociales}

La reestructuración impulsada desde el golpe militar de 1973 -y, especialmente, a partir de 1975, cuando se adoptó un consistente conjunto de políticas de liberalización y desregulación- estuvo orientada básicamente a tratar de desmantelar el aparato institucional y productivo establecido en el período en que habían imperado las políticas de corte keynesiano y a sentar las bases de un nuevo modelo de crecimiento. Bajo este nuevo enfoque, desde mediados de la década de los 80 , una vez transcurridos los años más duros de la reestructuración y ya restablecidos los principales equilibrios macroeconómicos, comenzó una etapa de fuerte crecimiento, con tasas que alcanzaron un promedio de $6.6 \%$ entre 1984 y 1989 , para elevarse a $7.4 \%$ entre 1990 y 1998, período en el que también se registró un importante crecimiento del sector industrial.

La transformación de la estructura económica nacional ocurrida en estos años se reflejó en una caída de la contribución de los sectores agrícola e industrial a la generación de empleos: en tanto entre 1986 y 1996 el empleo agrícola descendió desde el $20.6 \%$ al $15.4 \%$, la industria, cuya mayor contribución corresponde al período de auge de la industrialización sustitutiva cuando llegó a generar más del 30\% del empleo nacional -luego de una relativa "desindustrialización" en la primera fase de la aplicación de estas políticas y pese a la posterior recuperación del crecimiento del sector- en la última década apenas ha logrado contribuir con algo más del 16\% del total de los empleos. Al mismo tiempo se produjeron cambios importantes en el sector servicios, donde el crecimiento de los empleos generados por las actividades de transporte y comunicaciones, comercio y servicios financieros, compensaron la caída del empleo público ocasionada por las políticas de desburocratización que formaron parte de la reforma del Estado. Estos cambios acentuaron aún más la tendencia a la urbanización del empleo, iniciada en el período de auge de la industrialización sustitutiva.

Así mismo, la dinámica económica que se fue perfilando al avanzar la reestructuración y la globalización estuvo asociada a sustanciales cambios en las condiciones generales de funcionamiento del mercado laboral y tuvo importantes efectos sobre la evolución del empleo y la estructura ocupacional. Estos cambios estuvieron condicionados por las medidas adoptadas por el Gobierno Mi- litar con el propósito de desmontar el conjunto de arreglos institucionales sobre relación salarial establecidos en el período anterior, medidas que culminaron con la sanción, en 1979, de un Código de Trabajo estructurado en función de criterios de liberalización y flexibilización de los mercados laborales, cuyas disposiciones básicas han permanecido vigentes desde entonces.

Con este marco institucional desregulado como telón de fondo e impulsado por el elevado crecimiento observado desde mediados de la década de los 80 , se produjo un significativo aumento de la generación total de puestos de trabajo, que se concretó en la creación neta de más de 1.400.000 empleos durante el período 1986-1996, lo que incidió en una caída de la tasa de desempleo desde $10.4 \%$ en 1986 a 5.4\% en 1996 (OIT, 1998). Este proceso fue acompañado por un sostenido aumento del ingreso per cápita, que se elevó desde 1.360 a 5.151 dólares entre 1985 y 1997, que se tradujo en un sustancial aumento del ingreso de los hogares $\mathrm{y}$, consecuentemente, en una progresiva dinamización del mercado interno.

En este contexto, la situación social chilena experimentó importantes mejoras a lo largo de estos años, como lo indica, ante todo, el que entre 1987 y 1998 se haya registrado una significativa reducción de los niveles nacionales tanto de pobreza como de indigencia, disminuyendo los primeros desde $45.1 \%$ del total en 1987 a $21.7 \%$ en 1998 , en tanto que en el mismo lapso la población en situación de indigencia, se redujo desde $17.4 \%$ a $5.6 \%$. En el mismo sentido, se observa que, al consolidarse la recuperación económica, Chile registró avances significativos en su nivel de desarrollo, como lo muestran las evaluaciones sobre Desarrollo Humano, que para 1998 lo ubicaban en el segundo lugar, después de Argentina, entre las economías emergentes latinoamericanas (PNUD, 2000).

No obstante el mejoramiento general que expresa la mayor parte de estos indicadores, la informalidad y la precarización permanecieron como atributos significativos del mercado de trabajo chileno. En lo que se refiere al primer aspecto, se observó una persistente importancia de la ocupación informal en la estructura del empleo, puesto que no, obstante las elevadas tasas de crecimiento económico y el buen desempeño del mercado laboral, el mismo continuaba incluyendo el $39.5 \%$ del empleo total del sector (servicio doméstico incluido) en 1996, lo que resulta importante al momento de evaluar la situación general del mercado laboral, habida cuenta que los hogares más pobres están sobrerrepresentados en este sector (OIT, 1998:94-96). 
En cuanto a la flexibilización de los contratos de trabajo, los resultados de una encuesta laboral a empresas realizada a comienzos de 1998 permitió comprobar que "3 de cada 10 trabajadores, contratados directamente o subcontratados, tienen trabajo temporal y sólo una cuarta parte de los nuevos contratos es de carácter indefinido" y que "la composición de las nuevas contrataciones (las que se produjeron durante los 12 meses anteriores a la encuesta) ratifica el dato sobre la preeminencia de los contratos temporales sobre los indefinidos. Del total de las nuevas contrataciones sólo el 24\% fueron contratos indefinidos (...)" (ENCLA, 1998:5). Este porcentaje resulta excesivamente elevado, especialmente si se considera que al ser esta una encuesta a empresas, ella no incluye al sector informal.

Pese al elevado crecimiento económico alcanzado en este período y la intensificación de las políticas sociales impulsadas por los gobiernos democráticos, no fue posible modificar sustantivamente el patrón de desigualdad social heredado, en el que coexisten sectores sociales que experimentan una movilidad social ascendente y una mejora apreciable en sus condiciones de bienestar, con un importante sector de trabajadores con empleo precario y grupos marginales con escasas posibilidades de mejorar su ubicación en el espectro social. Ello se refleja en el hecho de que no se observen indicios importantes de reversión en la regresiva distribución del ingreso heredada ${ }^{3}$ (Cuadro 1), lo que hace que Chile continúe apareciendo como uno de los países con peor distribución del ingreso en América Latina (Cowan y De Gregorio, 1996).

En todo caso, también debe tenerse en cuenta que, si se considera la distribución del ingreso monetario que incluye los subsidios estatales debidos a las políticas sociales, la desigualdad entre los sectores de mayores y menores ingresos tiende a disminuir en forma importante. En este sentido, Cowan y De Gregorio (1996:30) ya habían comprobado que "la política fiscal, a través del gasto público en educación y salud, ha tendido a compensar de manera creciente la desigual distribución del ingreso". Más recientemente, un estudio realizado por Contreras y Bravo para el período 1990-96, concluye que, cuando se consideran como ingresos las políticas sociales impulsadas por el gobierno, la desigualdad entre el $20 \%$ más rico y el $20 \%$ más pobre se reduce en forma significativa (El Diario, 27 octubre 1999).

\section{Reestructuración, Inserción Externa y Globalización}

Los elementos de juicio mencionados hasta aquí avalan la conclusión de que, no obstante el handicap que se deriva de la reducida dimensión de su mercado interno, en este período Chile dio pasos importantes en materia de crecimiento, desarrollo humano y mejoría de las condiciones generales de vida de su población, aún cuando sin lograr alterar significativamente su regresiva distribución del ingreso. En este cuadro, como consecuencia de los avances alcanzados en la modernización capitalista del país, se fue produciendo una sostenida profundización de la inserción de la economía nacional en una economía-mundo que ya se encontraba en progresiva e incontenible globalización. Este aspecto tiene una importancia fundamental en la reactivación del crecimiento metropolitano en torno a la ciudad de Santiago.

Los cambios operados en el comercio exterior y en la inversión directa extranjera (IDE) permiten una primera aproximación a la magnitud de los cambios en el nivel de inserción externa de la economía chilena: entre 1982 y

\section{CUADRO 1}

Distribución del Ingreso Autónomo de los Hogares por Decil del Ingreso Autónomo per cápita del Hogar (1) Chile - 1990-1998

\begin{tabular}{|c|c|c|c|c|c|c|c|c|c|c|c|c|}
\hline Decil (2) & 1 & 2 & 3 & 4 & 5 & 6 & 7 & 8 & 9 & 10 & Total & $9+10 / 1+2$ \\
\hline 1990 & 1,4 & 2,7 & 3,6 & 4,5 & 5,4 & 6,9 & 7,8 & 10,3 & 15,2 & 42,2 & 100,0 & 14,0 \\
\hline 1992 & 1.5 & 2,8 & 3,7 & 4,6 & 5,6 & 6,6 & 8,1 & 10.4 & 14,8 & 41.9 & 100,0 & 13,2 \\
\hline 1994 & 1,3 & 2,7 & 3,5 & 4,6 & 5,5 & 6,4 & 8,1 & 10,6 & 15,4 & 41,9 & 100,0 & 14,3 \\
\hline 1996 & 1,3 & 2,6 & 3,5 & 4,5 & 5,4 & 6,3 & 8,2 & 11,1 & 15,5 & 41,6 & 100.0 & 14,6 \\
\hline 1998 (3) & 1,2 & 2,5 & 3,5 & 4,5 & 5,3 & 6.4 & 8,3 & 11,0 & 16,0 & 41,3 & 100,0 & 15,5 \\
\hline
\end{tabular}

Fuente: MIDEPLAN (1999), Encuestas CASEN.

(1) Se excluye al servicio doméstico puertas adentro y su núcleo familiar.

(2) Deciles construidos a partir del ingreso autónomo per cápita del hogar.

(3) Cifras preliminares. 
1997, las exportaciones de bienes pasaron de 3.710 a 16.923 millones de dólares, en tanto que las importaciones evolucionaron desde 3.643 a 18.218 millones de dólares. En ese mismo período, la IDE creció en forma persistente: mientras la acumulada entre 1974 y 1989 llegó a un total de U\$S 5.105 millones, la correspondiente al lapso comprendido entre los años 1990 y 1998 alcanzó a los U\$S 24.594 millones. Esta evolución ha llevado a que la relación entre IDE y PIB, para cada año entre 1990 y 1996, sea la más elevada entre las economías emergentes, grandes y medianas, latinoamericanas (Cuadro 2).

Por otra parte, al mismo tiempo que se observaba una creciente conglomeración del capital en torno a grupos económicos de gran diversificación horizontal, que aglutinaban una amplia gama de los rubros que mostraron mayor dinamismo en este período, también avanzó con fuerza la transnacionalización del aparato productivo chileno, donde actividades claves como minería, comunicaciones, electricidad, etc., rápidamente lograron contar con una alta participación de capital extranjero y donde muchas de ellas terminaron por quedar totalmente bajo su control directo. Este fenómeno continuó intensificándose a medida que el nuevo modelo se fue consolidando, afectando no solamente a actividades como las mencionadas, sino también a un número cada vez mayor de las empresas orientadas a la exportación, así como a los servicios más vinculados al sector globalizado de la economía (especialmente, servicios bancarios y financieros, comercio, transporte, turismo, etc.). En este período también se incrementaron en forma sustantiva las inversiones chilenas en el exterior, especialmente en países vecinos como Argentina y Perú, lo que aparece como otra manifestación de dicho proceso de creciente inserción externa.

En esta dirección, resulta importante comparar el nivel de inserción en la nueva dinámica capitalista globalizada de este país con el de otras economías emergentes medianas y grandes de la región (Cuadro 2). A este respecto, ante todo, merece destacarse el hecho de que Chile aparezca desde hace varios años como el país latinoamericano mejor ubicado en distintos rankings de competitividad (tanto en el realizado por el World Economic Forum, como en el del International Institute for Management Development). Lo mismo ocurre con las evaluaciones de riesgo-país realizadas por las más importantes calificadoras internacionales en esta materia, donde Chile continúa detentando la mejor calificación en el ámbito latinoamericano.

Otro indicador relevante en la misma dirección es el relativo al número de empresas chilenas incluidas entre las 90 latinoamericanas que, en 1997, cotizaban acciones en la Bolsa de Valores de Nueva York, a través de los American Depositary Receipts (ADRs), que entonces superaba al correspondiente al de los restantes países considerados. Este indicador parece especialmente importante si se considera que es, justamente en el plano de la integración financiera mundial, donde se verifica una de las dimensiones fundamentales de la globalización.

CUADRO 2

Indicadores de Inserción Internacional en

Economías Emergentes Latinoamericanas Grandes y Medianas 1990-1998

\begin{tabular}{|c|c|c|c|c|c|c|c|}
\hline Países & $\begin{array}{c}1 \\
\text { Competitividad } \\
1998\end{array}$ & $\begin{array}{c}2 \\
\text { Riesgo-Pais } \\
1998\end{array}$ & $\begin{array}{c}3 \\
\text { IDE como \% } \\
\text { del PIB } \\
\text { 1990-96 }\end{array}$ & \begin{tabular}{l}
\multicolumn{1}{c}{4} \\
Part. 500 \\
"América \\
Economía"
\end{tabular} & $\begin{array}{c}5 \\
\text { Part. } 200 \\
\text { "Business Week" } \\
1998\end{array}$ & $\begin{array}{c}6 \\
\text { Part. } \\
90 \text { ADR } \\
1997\end{array}$ & $\begin{array}{c}7 \\
\text { Poder de } \\
\text { Compra } \\
1996\end{array}$ \\
\hline Argentina & 36 & BB & 1.58 & 73 & 8 & 16 & 194.6 \\
\hline Brasil & 46 & $\mathrm{~B}+$ & 0.47 & 243 & 27 & 21 & 438.7 \\
\hline Chile & 18 & A- & 2.30 & 32 & 9 & 22 & 44.4 \\
\hline Colombia & 47 & BBB- & 1.78 & 27 & 1 & - & 55.8 \\
\hline México & 32 & BB & 1.74 & 102 & 22 & 21 & 175.0 \\
\hline Perú & 37 & BB & 1.58 & 5 & 1 & 5 & 43.2 \\
\hline Venezuela & 45 & B & 1.44 & 13 & 2 & 5 & 53.9 \\
\hline
\end{tabular}

Fuentes: 1) Ubicación en el ranking de competividad 1998: World Economic Forum, 1998 (El Mercurio, Santiago, 10/junio/1998); 2) Evaluación Riesgo-País a largo plazo según Standard \& Poor's (América Economía, 6/mayo/1999); 3) Inversión Directa Extranjera como porcentaje del PIB, 1990-96: CEPAL, 1997; 4) Empresas incluidas en ranking de América Economía: América Economía, noviembre 1997; 5) Empresas incluidas en "The Top 200 Companies of Emerging Markets" del Business Week: Business Week, Latin American Edition, july 13, 1998; 6) Participación en los 90 ADR latinoamericanos de mayor patrimonio bursátil: América Economía, noviembre 1997; 7) Poder de compra en América Latina en 1996 en US\$ miles de millones: Strategy Research Corporation, Latin American Market Planning Report (América Economía, diciembre 1997). 
Complementariamente, también puede mencionarse la relativamente alta cantidad de empresas chilenas incluida en diversos rankings realizados al respecto (por ejemplo, las 500 mayores latinoamericanas de América Economía y las 200 "top" de los países emergentes de Business Week (Cuadro 2), lo cual constituye un reconocimiento de la importancia relativa que han ido adquiriendo estas empresas en el ámbito del desarrollo capitalista periférico globalizado.

En su conjunto, los indicadores considerados dan una idea sobre el nivel de inserción-articulación en la dinámica globalizada lograda por este país luego de más de dos décadas de aplicación de la estrategia de liberalización y apertura y, también, sobre los avances en términos de modernización capitalista logrado por una parte importante de su aparato productivo. El conjunto de cambios estructurales resultantes de este proceso, que se caracteriza por la desaparición, aparición y/o transformación de un cúmulo de actividades y funciones económicas, hace posible hablar de la formación de una nueva base económica esencialmente urbana. ¿Cuál ha sido la incidencia de estas transformaciones sobre la estructura territorial nacional y, en particular, sobre el AMS? Desde la perspectiva de este trabajo, nos interesa centrar la atención en las implicancias del hecho de que las preferencias locacionales de buena parte de las principales nuevas actividades y funciones, surgidas al amparo de la reestructuración productiva y de la globalización, establecieron condiciones propicias para que se desencadenase un nuevo ciclo de crecimiento y expansión metropolitana.

En ese sentido, una de las hipótesis centrales de este trabajo es que esta nueva fase de crecimiento y expansión del AMS está condicionada por la forma en que la inserción-articulación en la dinámica global incidió en la redefinición de la naturaleza de las actividades y funciones de su base económica, y también, por como las tendencias locacionales predominantes entre estas actividades y funciones están asociadas, principalmente, a diversos factores o condiciones existentes y ofrecidas por el AMS, que hacen que ella termine ejerciendo una mayor atractividad que otras partes del territorio. En lo fundamental, esta actractividad es ejercida sobre las principales actividades/funciones articuladoras entre la economía nacional y la global, así como sobre una parte relevante del nuevo aparato productivo capitalista. En otras palabras, el nuevo impulso al crecimiento metropolitano resulta fundamentalmente de la marcada preferencia de las actividades más representativas del nuevo poder económico conformado al ritmo de la globalización (donde los grandes grupos económicos y las empresas transnacionales juegan un papel central) por localizarse en esta parte del territorio nacional (de Mattos, 1995).

\section{NUEVAS TENDENCIAS LOCACIONALES Y RECUPERACIÓN DEL CRECIMIENTO METROPOLITANO}

Fue desde mediados de la década de los 80 cuando se empezaron a observar indicios de un retorno de las tendencias a la concentración económica y demográfica en torno a Santiago. Ya se habían producido entonces los principales cambios en la base económica metropolitana, donde luego de la desaparición de numerosas industrias no competitivas en una economía abierta, había comenzado la irrupción y el crecimiento de un conjunto de actividades vinculadas tanto a la dinámica globalizada, como a los requerimientos de un mercado interno en expansión. En lo fundamental, este proceso se materializó en una pérdida de importancia relativa de la industria en la respectiva estructura productiva, tanto en su contribución al PIB (Cuadro 3) como al empleo, y por un sostenido crecimiento de los servicios, entre los que el comercio, el transporte, las comunicaciones y los servicios financieros aparecieron como los componentes más dinámicos. Si bien los servicios ya tenían una alta presencia en la estructura productiva del AMS en el período anterior, su participación continuó aumentando ahora bajo los efectos de la reestructuración, adquiriendo mayor relevancia algunos de los componentes más fuertemente vinculados a la dinámica globalizada.

Fue a impulsos de esta economía urbana predominantemente terciarizada que se produjo la recuperación y

\begin{tabular}{|c|c|c|c|c|c|c|}
\hline \multicolumn{7}{|c|}{$\begin{array}{c}\text { Cambios en la Estructura del PIB } \\
\text { Chile }-1960-1996\end{array}$} \\
\hline \multirow{2}{*}{ Sector } & \multicolumn{6}{|c|}{ Promedios Trienales } \\
\hline & $1960-62$ & 1970-72 & 1980-82 & $1985-87$ & 1990-92 & $1994-96$ \\
\hline Pais & 100,0 & 100,0 & 100,0 & 100,0 & 100,0 & 100,0 \\
\hline Agropecuario, & & & & & & \\
\hline Pesca y Minería & 3,7 & 3.0 & 3,9 & 4,1 & 4,2 & 3,7 \\
\hline Industria & 26,3 & 26,8 & 20,8 & 21,2 & 21,6 & 20,8 \\
\hline Construcción & 8,0 & 5,9 & 6,2 & 4,7 & 5,6 & 5,5 \\
\hline Servicios & 61,9 & 64,3 & 69,0 & 69,8 & 68,7 & 69,9 \\
\hline
\end{tabular}

Fuente: Elaborado con base en CIEPLAN/SUBDERE y Banco Central. 


\begin{tabular}{lcc}
\multicolumn{4}{c}{$\begin{array}{c}\text { CUADRO 4 } \\
\text { Participación RMS en PIB y PIB Industrial } \\
\text { Chile - 1970-1996 }\end{array}$} \\
\hline Años & PIB Chile & PIB Industrial \\
\hline $1970 / 72$ & 47,8 & 51,0 \\
1975 & 42,3 & 43,2 \\
1980 & 44,9 & 44,0 \\
1985 & 42,1 & 43,5 \\
1990 & 45,1 & 48,9 \\
1996 & 47,7 & 51,6 \\
\hline
\end{tabular}

Fuente: CIEPLAN/SUBDERE (1995) y Banco Central de Chile.

afirmación de una nueva fase de crecimiento y expansión metropolitana, básicamente condicionada por los requerimientos locacionales de las más importantes actividades que la conformaban. Entonces la tendencia a la concentración productiva en la RMS fue adquiriendo fuerza, con lo que logró recuperar e, incluso, en algunos casos, superar los niveles de concentración productiva que había mostrado en la fase culminante de la industrialización sustitutiva. Esto puede apreciarse através de la evolución tanto del PIB total, como del PIB industrial de la RMS, que muestra una trayectoria en forma de U (Cuadro 4), en la que ambos indicadores, luego de una importante caída al comenzar la reestructuración, llegan a su punto más bajo hacia mediados de esta década, para volver a crecer a partir de allí, hasta alcanzar valores equivalentes a los más altos del pasado.

Esta trayectoria indica que en la primera fase del proceso de reestructuración, junto a la declinación de buena parte de los componentes del viejo aparato productivo del AMS, se produjo un mayor crecimiento de otros lugares que contaban con ventajas comparativas para la producción y procesamiento de recursos naturales exportables, lo que pareció confirmar circunstancialmente las previsiones del discurso que anticipaba una mayor dispersión territorial de las actividades productivas. A ello se sumó el hecho de que como, en el pasado, la industria sustitutiva se había localizado mayoritariamente donde se encontraba la parte cuantitativa y cualitativamente más importante del mercado interno, esto es, en la aglomeración principal del país, su declinación afectó en mayor grado al AMS y a su entorno de influencia directa que a otros lugares del territorio nacional.

Sin embargo, al iniciarse una fase de elevado y sostenido crecimiento y producirse la formación de la nueva base económica -donde, como ya hemos señalado, los servicios comenzaron a adquirir una creciente importancia- se establecieron condiciones favorables para una nueva fase de crecimiento productivo metropolitano. Entonces, se pudo observar que las empresas vinculadas a la parte más moderna y dinámica de esta nueva base económica -en busca de condiciones propicias a un mayor crecimiento de la productividad y de la rentabilidad- volvían a mostrar una marcada preferencia por localizarse en la principal aglomeración urbana del país. Esta tendencia locacional respondió a la existencia de un conjunto de factores que otorgaron al AMS una atractividad $^{4}$ superior a la que poseían los restantes centros urbanos. En lo fundamental, esa mayor atractividad se puede atribuir a la presencia en este lugar de:

- mejores y más expeditos sistemas de comunicaciones, capaces de permitir contactos cotidianos fluidos con empresas relacionadas en distintos lugares del entorno global (red integrada de comunicaciones con el exterior, aeropuerto internacional de primer nivel, amplia disponibilidad de vuelos hacia otros nodos de la red global, etc.);

- actores de equivalente rango jerárquico, dado que para las cúpulas de los grandes grupos y empresas que se consolidaron en esta fase, fue un importante handicap tener una localización distante del lugar donde se concentraba la mayoría de las otras del mismo nivel;

- condiciones para una más fluida comunicación directa cotidiana (face to face), formal e informal, entre las personas vinculadas a las tareas más modernas e innovadoras, que permiten potenciar los "beneficios creativos de la proximidad" (Reich, 1991);

- oferta diversificada y eficiente de servicios especializados de punta, imprescindibles para el desarrollo de las actividades de otras empresas industriales y de servicios que pugnaban por asegurar una presencia competitiva en los mercados globales;

- tejido productivo más amplio y diversificado, en el que las nuevas actividades -en especial, las industrialespodían contar con la existencia y proximidad de los otros tipos de productores requeridos para concretar los eslabonamientos considerados por sus respectivos procesos productivos y para materializar las respectivas subcontrataciones;

- mercado amplio y diversificado directamente accesible, tanto de compradores como de proveedores;

- amplia disponibilidad de recursos humanos, tanto calificados como no calificados, donde los del primer tipo han venido adquiriendo una importancia creciente. ${ }^{5}$

La atractividad ejercida por factores de esta naturaleza involucró tanto a las actividades a cargo del comando de la 
gestión y la coordinación de la parte central del proceso de acumulación, como también a las ramas más modernas y dinámicas de los servicios y de la industria. ¿Qué nos indica la evidencia empírica a este respecto? En primer término, que fue en el AMS donde se establecieron las más importantes funciones de dirección general, planificación y control del aparato productivo emergente, esto es, el comando de la gestión y la coordinación del proceso de acumulación y de las actividades centrales de enlace y articulación de la economía nacional con la global. Por consiguiente, prácticamente la totalidad de las sedes corporativas centrales de los principales grupos económicos y grandes empresas están localizadas en el AMS y, principalmente, en su área central, aún cuando en los últimos años se ha comprobado una importante tendencia a desplazarse hacia otras comunas del oriente de la ciudad.

Por las mismas razones, también es en el AMS donde están ubicadas las sedes corporativas y oficinas centrales de la enorme mayoría de las empresas transnacionales que operan en el país y cuyos edificios corporativos constituyen hitos relevantes del paisaje urbano emergente. Directamente correlacionado con ello, también se puede comprobar que tiene su localización en este lugar, la totalidad de las más importantes sedes centrales de las asociaciones corporativas de la empresa privada, como es el caso de las relacionadas con la producción, el comercio, la industria e, incluso, la agricultura y la minería. A ello cabría agregar todavía, el hecho de que es en el AMS donde tiene su sede la cúpula del aparato burocrático de un Estado aún escasamente descentralizado.

Es así que, luego de la crisis de 1982-83, al intensificar su condición de área principal de localización de las funciones de articulación y operación de las relaciones entre el aparato productivo nacional, el AMS reafirmó su condición de principal nodo chileno de la red global de ciudades; de esta manera, pasó a cumplir, a su escala, un papel equivalente al de una ciudad global (Sassen, 1991), reforzando su condición de lugar privilegiado para la localización de las actividades más directamente vinculadas con la dinámica de la globalización, con todas las consecuencias que esto tiene en materia de eslabonamientos productivos y de generación de empleos.

En segundo término, también los servicios más modernos y con mayor vinculación a las actividades globalizadas tendieron a localizarse preferentemente en el AMS, lo cual corresponde a un comportamiento de carácter universal ${ }^{6}$ que indica que los servicios tienen una marcada propensión a organizarse en forma centralizada y a concentrarse en las áreas metropolitanas principales, en todos los países donde han avanzado los procesos de terciarización (Bailly y Coffey, 1994). A este respecto en particular cabe destacar que prácticamente la totalidad de la cúpula de las actividades y funciones del sistema financiero está localizada en AMS, lo que involucra a todas las casas matrices de los bancos nacionales, las sedes centrales de los bancos extranjeros y las sedes de las instituciones financieras transnacionales, así como de los fondos de pensiones y de las empresas de seguros. A ello cabría agregar que es en este lugar donde se realiza alrededor del $97 \%$ de las operaciones del mercado de valores, a través de la Bolsa de Comercio de Santiago y de la Bolsa Electrónica, lo que opera como un verdadero imán para la localización de otros servicios financieros en su proximidad física.

Por otra parte, también se encuentra localizada en el AMS la parte más moderna de los otros servicios al productor (asistencia jurídica, consultoría, publicidad, "marketing”, informática, etc.), cuyo crecimiento y diversificación se produjo al unísono con la reconversión y recuperación industrial. Esta concentración de servicios, a su vez, ha impulsado la creación en este lugar de una infraestructura para actividades conexas (como centros para eventos internacionales, hoteles, restaurantes, etc.), así como el desarrollo de actividades orientadas a la capacitación empresarial de más alto nivel. Además, también muestran el mismo comportamiento locacional los servicios vinculados directamente a actividades y productos globales, cuya irrupción y generalización se intensificó rápidamente bajo el efecto combinado de la apertura externa y la recuperación económica. A ello se suma que, dada la fuerte concentración territorial de la parte más solvente del mercado interno en la RMS, en cuya área de influencia directa reside más del $50 \%$ de la población nacional, sea aquí donde se instalaron, exclusiva o predominantemente, numerosas actividades destinadas a la comercialización de un diversificado conjunto de productos y servicios globales, incluyendo desde los últimos avances en materia de nuevas tecnologías y lo más sofisticado de la moda y la alta costura, la hotelería, la gastronomía, etc., hasta una variada oferta de establecimientos de comida rápida.

Finalmente, se puede comprobar que los establecimientos manufactureros también mostraron una recuperación de su propensión a localizarse mayoritariamente en el AMS, la que fue más acentuada para el caso de las ramas industriales con un dinamismo superior al promedio (de Mattos, 1996; Riffo y Silva, 1998). Para este período, los indicadores de 
concentración territorial disponibles para la industrias de más de 10 trabajadores, muestran que la RMS continua siendo el lugar que genera el mayor volumen de ocupación media industrial del país: $55 \%$ del total en 1985 a $55.5 \%$ en 1997; por su parte, las cifras correspondientes al valor agregado industrial documentan un aumento más fuerte de la participación de la RMS, la que, en 1985, generaba el 36,5\% del mismo, para aumentar al 45.8\% en 1997.

Por lo tanto, al culminar el proceso de reestructuración en Chile, el AMS se ha constituido en el lugar en que se ha emplazado la mayoría de las actividades de mayor jerarquía de la nueva base económica urbana:

- el comando del nuevo poder económico (que incluye a los principales grupos económicos y a las empresas multinacionales que operan en el país), incluyendo las funciones de enlace con la economía mundo;

- la cabeza y las principales actividades del sector terciario moderno, en el que destacan los servicios a la producción;

- la parte más avanzada y diversificada del mercado de productos globales; y

- un porcentaje mayoritario de la nueva industria y, en particular, de la más dinámica y con mayor capacidad innovadora.

La localización conjunta de estas actividades en el AMS ha conformado una base económica de continuado dinamismo en la que se sustenta un mercado metropolitano de trabajo que reúne la mayor parte de los empleos de más elevada remuneración del país. La presencia de este mercado se ha traducido en una creciente demanda por nuevos productos o artefactos urbanos, cuya realización también ha contribuido a dar mayor impulso al crecimiento metropolitano; tal es el caso de edificios con equipamiento avanzado ("edificios inteligentes") tanto para actividades empresariales como comerciales y residenciales, edificios y equipos de alto estándar para la educación y la atención de la salud, especialmente para sectores de ingresos altos y medios-altos, sistemas de comunicaciones y de transportes modernos y eficientes, infraestructura para un comercio diversificado y especializado, aeropuerto internacional de primer nivel, etc., cuya materialización está incidiendo en una acentuación de la brecha entre esta aglomeración y el resto de las ciudades nacionales.

En síntesis, al irse articulando la parte más importante del aparato productivo nacional en un vasto conjunto de redes globales financieras, productivas, tecnológicas, culturales, etc., Santiago se fue consolidando como el principal foco receptor de las principales funciones y actividades de enlace de Chile con el resto del mundo, con lo que fue afirmando su condición de ciudad en proceso de globalización. ${ }^{7}$ En este proceso, la profunda transformación que se produjo en su base económica otorgó un nuevo impulso a su crecimiento económico y expansión metropolitana. A su vez, esa nueva base económica metropolitana, al mismo tiempo que se constituyó en la plataforma básica que impulsó una mejor articulación de Santiago en la red mundial de ciudades, ha operado como un foco de atracción para la localización de nuevas inversiones y actividades, no solamente en el AMS, sino también en el país en su conjunto, por lo que la continuidad de su crecimiento aparece como un factor importante para el de todo el país en el contexto de la economía globalizada. ${ }^{8}$ En esta dinámica, puede preverse que, en la medida en que Chile continúe creciendo y avanzando en su modernización capitalista y globalización, seguramente, el papel de Santiago como nodo secundario de la nueva estructura territorial que caracteriza al capitalismo global continuará fortaleciéndose.

\section{METROPOLIZACION EXPANDIDA: HACIA UNA METROPOLI-REGION}

¿Cómo se han materializado las tendencias al crecimiento metropolitano en este nuevo escenario? ¿Qué diferencias se perciben en las formas actuales de expansión metropolitana con respecto a las del período anterior? En lo fundamental, parece importante destacar ciertos rasgos que si bien no pueden considerarse como estrictamente novedosos, pues algunos de ellos ya habían comenzado a manifestarse en el período precedente, su intensificación y generalización es lo que podría considerarse como lo nuevo de la actual fase de metropolización:

- acentuación incontrolable de la tendencia a la suburbanización, con la formación de un periurbano difuso, de baja densidad, que prolonga la metrópoli en todas las direcciones en que ello es posible;

- afirmación de una estructura metropolitana polarizada y segregada, donde la estratificación social tiene una perfecta lectura territorial;

- irrupción de un conjunto de nuevos artefactos urbanos, con gran capacidad para (re)estructurar el espacio metropolitano.

\section{Suburbanización y Metropolización Expandida}

Cuando hacemos referencia al tema relativo a metropolización y suburbanización, resulta importante 
tener presente que estos no son fenómenos nuevos en el crecimiento de Santiago, puesto que ya se habían manifestado con fuerza bajo el impulso de la industrialización sustitutiva, momento en que había cobrado singular impulso el proceso de expansión metropolitana. En efecto, en tanto Chile formó parte del grupo de países latinoamericanos que realizaron los primeros esfuerzos por adoptar estrategias de corte keynesiano para promover una industrialización orientada a sustituir importaciones, el avance de estos esfuerzos redundaron en una intensificación de la urbanización y de la metropolización (Hurtado, 1966; Geisse, 1983; Rodríguez Vignoli, 1993). Es así que, ya en 1960, Santiago registraba una población de 1:907.378 habitantes, que representaba al $25.9 \%$ de la población del país. Diez años más tarde, este fenómeno comenzó a ser preocupante, como revela un importante estudio, en el que se afirmaba: “el alto grado de primacía y el rápido crecimiento relativo de la Región Central, comparada con el resto del país, corresponde, casi exclusivamente, a la primacía y desarrollo de la ciudad de Santiago. El proceso de concentración de población y actividades que ha sido especialmente intenso en las últimas décadas, ha significado que, en los últimos treinta años, la ciudad haya crecido desde un millón a tres millones de habitantes, es decir, hasta cerca de un tercio de la población nacional, en 1970, contra sólo un $18 \%$, en 1940 , y un $14 \%$ en 1920. En términos económicos, la ciudad de Santiago representa el $54 \%$ del total del valor agregado por el sector industrial, y la provincia de Santiago poco menos del 45\% del producto nacional bruto (contra un 60\% de la Región Central en conjunto)" (CIDU, 1972:10).

Más allá de ciertas oscilaciones, durante las últimas décadas, este proceso ha mostrado una gran persistencia y continuidad, tanto en lo que se refiere a crecimiento demográfico como territorial, con un ligero ascenso de la densidad en el conglomerado urbano (Cuadro 5). Obviamente, desde el punto de vista de la concentración de la población, el proceso ha venido perdiendo fuerza como consecuencia, por una parte, de que a medida que se ha elevado el nivel de urbanización, han tendido a atenuarse las migraciones internas $y$, por otra parte, de que ha venido cayendo la tasa de fecundidad (Rodríguez Vignoli, 1993), por lo que es lógico prever que el crecimiento de la población de la aglomeración seguirá evolucionando en los años venideros en forma mucho más lenta que en el pasado.

Lo específico de este último período es que ahora la metrópoli en expansión ha tendido a desbordar y desdibujar los límites urbanos consolidados en el período anterior, en un proceso en el que a partir del núcleo original, la mancha urbana ha continuado ocupando las áreas rurales que ha ido encontrando a su paso con asentamientos urbanos y semiurbanos, producto de operaciones inmobiliarias donde los diferentes estratos sociales aparecen claramente diferenciados (Romero y Toledo, 1998). Al mismo tiempo, ha completado la plena incorporación a la mancha metropolitana de diversos centros urbanos aledaños (San Bernardo, Maipú, Puente Alto, Quilicura) y ha articulado a otros a la dinámica metropolitana en calidad de ciudades satélites y/o barrios dormitorios (Rancagua, Melipilla, Talagante, Colina, Til Til, etc.). ${ }^{9}$ De esta manera, el área urbana heredada del periodo anterior, cuyos límites aparecian dibujados en forma más precisa y nítida, ha dado paso a una metrópoliregión, de estructura policéntrica y fronteras difusas, en persistente expansión, que ha ido adquiriendo una configuración tipo archipiélago.

Los datos correspondientes al período intercensal 19821992 (Cuadro 6), documentan la dirección e intensidad de este proceso expansión suburbana a través del crecimiento y distribución territorial de la población: mientras que el

CUADRO 5

Indicadores de Crecimiento

Chile y Gran Santiago - 1940-1992

\begin{tabular}{|c|c|c|c|c|c|c|}
\hline Indicadores & 1940 & 1952 & 1960 & 1970 & 1982 & 1992 \\
\hline Población Total & $5: 023.529$ & $5: 932.995$ & $7: 374.115$ & $8: 884.768$ & $11: 329.736$ & $13: 348.401$ \\
\hline Población Urbana & $2: 639.311$ & $3: 573.122$ & $5: 028.060$ & $6: 675.137$ & $9: 316.127$ & $11: 140.405$ \\
\hline \% Población Urbana & 52,5 & 60,2 & 68,2 & 75,1 & 82,2 & 83,5 \\
\hline Población Gran Santiago & 952.075 & $1: 376.584$ & $1: 907.378$ & $2: 820.936$ & $3: 902.356$ & $4: 754.901$ \\
\hline \% Población Gran Santiago & 19,0 & 23,2 & 25,9 & 31,8 & 34,4 & 35,6 \\
\hline Superficie Gran Santiago $\left(\mathrm{km}^{2}\right)$ & 110.17 & 153.51 & 211.65 & 318.41 & 420.80 & 492.70 \\
\hline Densidad Gran Santiago (hab x km²) & $8.641,87$ & $8.967,39$ & $9.011,94$ & $8.859,45$ & $9.273,66$ & $9,650,02$ \\
\hline
\end{tabular}

Fuente: Miranda Muñoz, 1997. 
núcleo urbano central de la ciudad, asentado en la Provincia de Santiago creció prácticamente a la misma tasa que el país en su conjunto, las cinco provincias restantes de la RMS que contornean a la de Santiago, lo hicieron a una tasa ampliamente superior al promedio nacional. En particular, cabe destacar el hecho de que, en todo el país, las dos provincias que mostraron mayores tasas de crecimiento de la población fueron las de Cordillera (109.7\%) y Chacabuco (58.9\%) contiguas a la Provincia de Santiago, en tanto que la Provincia de Maipo (39.6\%) solamente fue superada por el crecimiento de la de Copiapó (48.6\%). Esto indica que mientras el núcleo más antiguo de la ciudad tiende a estancarse en su crecimiento demográfico, es en las áreas adyacentes donde se manifiesta con más fuerza la expansión metropolitana.

Al considerar estas tendencias, parece importante destacar que, en comparación a los ritmos de crecimiento que se habían observado en décadas anteriores, cuando alcanzaron su mayor intensidad las migraciones rural-urbanas, ahora, este proceso se ha cumplido bajo una ralentización del crecimiento poblacional del AMS, que sólo pasó del $34.4 \%$ del total nacional, en 1982, al 35.6\%, en 1992. Esto permite afirmar que la expansión periurbana se debe, ante todo, a una redistribución de la población metropolitana, en la que parte de la misma desplaza su lugar de residencia hacia áreas suburbanas y donde una parte de la superficie ocupada adquiere carácter semiurbano (nuevos asentamientos residenciales bajo la forma de "parcelas de agrado"); de esta manera, la expansión de la superficie ocupada por la mancha metropolitana ya no es tan nítida y las mediciones tradicionales del área urbana no logran establecer su verdadera magnitud.

¿Cómo se puede explicar el desencadenamiento de este tipo de dinámica urbana? ¿Qué factores han tenido mayor

CUADRO 6

Crecimiento Demográfico por Provincias (1)

Chile - 1982-92 (Período Intercensal)

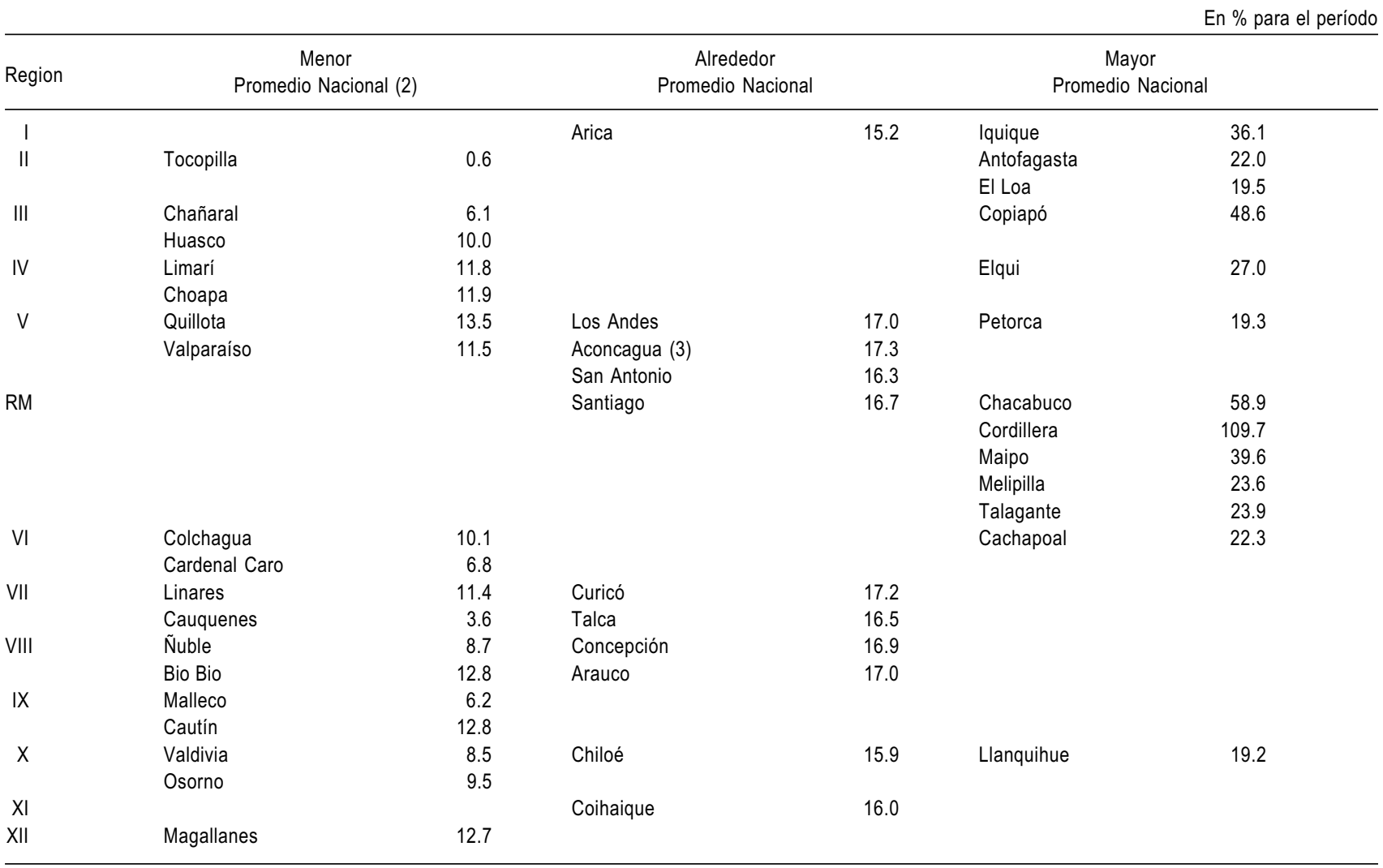

Fuente: Instituto Nacional de Estatísticas, Compendio Estatístico 1994.

(1) Solamente se incluyen provincias de más de 10.000 habitantes.

(2) En el periodo intercensal 1982-92 la población total de Chile creció en 16.8\%.

(3) Incluye San Felipe. 
incidencia en la intensificación de esta modalidad de expansión metropolitana? Ante todo, habría que destacar que las políticas de liberalización económica y de desregulación de la gestión urbana jugaron un papel crucial al respecto, en la medida que las reglas del juego que de alli se derivaron, contribuyeron en forma efectiva a remover los obstáculos que las regulaciones preexistentes establecian para que se desplegara una lógica estrictamente capitalista en la producción y la reproducción metropolitana. De hecho, la desregulación se propuso y logró desbloquear ciertas barreras que obstaculizaban las decisiones de los empresarios inmobiliarios y de las familias, cuyas preferencias y estrategias configuran la parte medular de las decisiones que dan cuerpo a la construcción de la ciudad en toda sociedad capitalista.

Complementariamente, tanto las condiciones establecidas por la apertura externa, como el progresivo aumento de los ingresos medios de las familias registrado en este período, contribuyeron a intensificar significativamente la utilización de dos productos característicos que adquirieron difusión generalizada en esta fase de la globalización: en primer lugar, el transporte automotor en especial, el automóvil- con un enorme impacto en la ampliación e intensificación de la movilización en el espacio metropolitano y, en segundo lugar, de las tecnologías de la información, que otorgaron mayor fluidez a las comunicaciones en ese ámbito. En el aumento de la utilización de estos productos, incidió fuertemente el hecho de que, al tiempo que se elevaron los ingresos personales, los precios de los mismos mostraron una tendencia a la baja como consecuencia de la apertura externa. En lo que sigue, revisaremos como estos factores profundizaron algunas tendencias que ya se habían manifestado en el período anterior, pero que ahora logran su máxima expresión.

\section{Liberalización y desregulación urbana}

En materia de gestión urbana, los principios de liberalización y desregulación fueron formalmente incorporados en una modificación al Plan Regulador Intercomunal, sancionada por el Decreto Supremo 420 de 1979. En esta instancia, se acogieron los planteamientos realizados por Arnold Harberger, economista de Chicago asesor del Gobierno Militar, quien consideraba al mercado como el factor determinante del desarrollo de las ciudades y sostenía que "el concepto normativo de 'límite urbano' era la causa del desequilibrio que conlleva la marcada diferencia entre valores del suelo urbano y rural" (Massone Mezzano, 1996:56).

Estos planteamientos fueron desarrollados, explicados y difundidos en un documento del Ministerio de la Vivienda y Urbanismo (MINVU) de 1979 sobre los "conceptos básicos para la formulación de la política nacional de desarrollo urbano", donde se resumían los fundamentos de la nueva modalidad de gestión urbana en los siguientes puntos:

- "es el sector privado el principal encargado de materializar las iniciativas de desarrollo urbano que demanda la población, mediante la generación de una adecuada oferta de bienes y servicios";

- la política debe "reconocer las tendencias del mercado como el principal indicador para determinar la cantidad de terreno que requerirá el desarrollo de las actividades urbanas y la dirección de crecimiento dominante";

- "el perímetro de crecimiento [urbano] futuro deberá seguir las tendencias preferenciales de localización que se expresen en el mercado, sin más restricciones que las que establezca el criterio general de la preservación del bien común [...]" (MINVU, 1981:23). De esta forma, se marcó una drástica ruptura con las ideas sobre planificación urbana que se habían impuesto en los años de la posguerra, donde se contemplaba un papel activo de las políticas públicas en el control del funcionamiento y de la expansión urbana, a través de instrumentos como los planes directores, en algunos casos con regulaciones sumamente estrictas.

Si bien esta versión extremadamente apegada al libre juego de las fuerzas del mercado en la construcción de la ciudad, tuvo un corto período de aplicación -pues, ya en 1985, el mismo Gobierno Militar le introdujo importantes modificaciones por las que se intentó una conciliación entre los enfoques normativo y adaptativo de la planificación- algunos de sus criterios básicos han permanecido vigentes hasta el día de hoy. Como se reconoce en un estudio posterior, "en el Chile de hoy, la gestión urbana se desenvuelve en un doble contexto: de un lado, en el propio de una economía de mercado con grados importantes de desregulación y privatización; de otro, en el marco dado por el proceso de descentralización política" (Daher, 1996:232).

En la medida que las intervenciones e inversiones públicas directas han tendido a reducirse drásticamente, $l a$ maximización de la plusvalía urbana se ha consolidado como el criterio urbanístico predominante, asumiendo una 
fuerza capaz de desbordar muchas de las regulaciones aún vigentes. Como resultado de ello se ha impuesto un proceso fragmentario de construcción de ciudad, donde las principales intervenciones urbanas surgen de iniciativas privadas aisladas, decididas en función de la rentabilidad esperada para cada una de ellas. En ese contexto, cada inversión busca la máxima utilización de cada fracción de suelo urbano dentro de lo que las regulaciones vigentes permiten. ${ }^{10}$

\section{Las estrategias y decisiones empresariales y familiares}

La aplicación de las políticas de liberalización económica y de desregulación despejaron el camino para que, tanto las estrategias empresariales como familiares pudiesen responder en mayor grado a sus respectivas preferencias e intereses. Así, las estrategias empresariales -que consideran al suelo metropolitano como un medio privilegiado para la valorización de sus capitalesintensificaron su incidencia en el proceso de construcción urbana. Desde el momento en que se percibió que la recuperación del dinamismo económico le devolvía al AMS su condición de sitio de localización de la parte más moderna y dinámica del aparato productivo nacional, así como de lugar de residencia de las capas sociales perceptoras de mayores ingresos, estas estrategias contemplaron un incremento significativo de la inversión privada en esta aglomeración. El hecho de que la mayoría de los grupos económicos chilenos, que tuvieron un significativo crecimiento en este período, haya incorporado el rubro de los negocios inmobiliarios como un componente especial de sus actividades (de Mattos, 1995), pone en evidencia la renovada importancia que se asigna a los mismos.

Complementariamente, las estrategias individuales o familiares, al desplegarse en una situación en la que habían desaparecido muchas de las regulaciones que acotaban el desarrollo urbano en el período anterior, pudieron desbordar con mucho mayor facilidad los límites de la ciudad, lo que tuvo importantes efectos en la redefinición de la modalidad de expansión metropolitana. Así, por un lado, los sectores de mayores ingresos impulsados por su marcada preferencia por la vivienda unifamiliar aislada $\mathrm{y}$, por otro lado, por su secular inclinación a poner la mayor distancia posible entre su lugar de residencia y aquel en que habitan los sectores populares e, incluso, ciertos sectores medios (González, Hales y Oyola, 1979), intensificaron sus desplazamientos hacia el oriente y, prin- cipalmente hacia los faldeos cordilleranos. El crecimiento de las áreas de residencia de estos sectores, que ha caracterizado sucesivas etapas de la evolución urbana de Santiago, ha estado marcado por su preferencia por las comunas de Providencia, Las Condes y Vitacura, a las que se ha incorporado la extensa Comuna de Lo Barnechea. A ello se suma, como expresión del deseo de evadirse de diversos problemas metropolitanos (contaminación, congestión, delincuencia, etc.), el aumento de los movimientos hacia ciertos lugares privilegiados más lejanos tanto al sur (Pirque), como al norte (Chicureo, Colina) de la ciudad, lo que ha terminado por dar un impulso adicional a la prolongación del periurbano y a una disminución general de la densidad urbana. Esta tendencia se ha concretado en la aparición de numerosos barrios y condominios exclusivos para primera o segunda vivienda, donde algunas de las denominadas "parcelas de agrado" tienden a ser concebidas según un modelo similar al de los barrios cerrados de ciertas ciudades norteamericanas, contribuyendo a intensificar la suburbanización y, de esta forma, a estimular la continuidad del fenómeno urbanoterritorial del que se quiere evadir. El conjunto de estos desplazamientos hacia áreas suburbanas, se ha traducido en la reiterada violación de algunas de las disposiciones remanentes para regular el crecimiento y el funcionamiento urbanos.

A su vez, los sectores medios, en especial aquellos que en los últimos años se han beneficiado de una elevación de sus presupuestos familiares (INE, 1999), han incidido en la renovación, expansión y/o consolidación de algunos barrios tradicionales de clase media (Ñuñoa, La Reina, La Florida, Maipú, etc.) en los que todavía quedaban áreas por edificar o densificar. Al mismo tiempo, la demanda de una parte importante de los grupos de medianos ingresos por viviendas con buenos servicios urbanos, ha incidido en el éxito de la operación promovida por la Alcaldía de la Comuna de Santiago para recuperar ciertas partes de Santiago Poniente, en una suerte de proceso de "gentrificación", ${ }^{11}$ a semejanza de como ha ocurrido en muchas ciudades norteamericanas (Smith, 1996). Pero, además, estos grupos también han marcado su presencia en la demanda por emprendimientos inmobiliarios en la periferia de Santiago (o en la costa para segunda vivienda) concebidos como recintos cerrados.

Finalmente, pese al relativo éxito de la política de vivienda impulsada por el gobierno para los sectores de menores ingresos, se puede comprobar que mayoritariamente ellos han podido tener acceso a soluci- 
ones habitacionales baratas, tanto en lo que concierne a diseño como a construcción, edificadas en terrenos reducidos, localizados en la periferia pobre de la ciudad, donde el precio de la tierra es más bajo. De hecho, “el Ministerio de la Vivienda o las empresas que concursan para realizar estos conjuntos habitacionales han comprado los terrenos de más bajo costo cuyas características son bastante similares a las de los terrenos invadidos en otros países: se localizan en la periferia urbana, alejados de cualquier centro de actividad, con suelos de mala calidad o con problemas como inundaciones, hundimientos, o en zonas de la ciudad poco atractivas por su cercanía a elementos urbanos molestos (basurales, pozos de áridos, plantas de tratamiento de aguas servidas, cementerios, etc.)" (Ducci, 1997:106). De tal manera, las viviendas de los pobres también contribuyeron a la suburbanización, estimulando una incesante y prácticamente incontrolada expansión de importantes áreas periurbanas.

Todo esto avala la conclusión de que los negocios inmobiliarios, al imbricarse dinámicamente con las preferencias de la población urbana, sea cual sea su nivel de ingresos, están jugando un papel fundamental en el reforzamiento de las tendencias a la suburbanización y periurbanización metropolitana.

La difusión del automóvil y de las

nuevas tecnologías de la información

Sin embargo, la metrópoli que se ha ido configurando bajo el efectos de las mencionadas estrategias empresariales y familiares no podría explicarse totalmente si no se considerase la incidencia de la generalización de los vehículos automotores y las nuevas tecnologías de la comunicación, producida básicamente bajo los efectos del aumento del poder adquisitivo de una parte importante de la población y de la caída de los precios respectivos a partir de la apertura externa.

Fue así que, acompañando la reactivación económica, se produjo un vertiginoso aumento de la tasa de motorización en todo el país y, en especial, en la RMS, consecuencia de la generalización de la utilización familiar e individual del automóvil y de un fuerte aumento del equipamiento para el transporte automotor. Conforme a datos del INE, solamente en el período 1992-1996, el número de automóviles en la RMS mostró un crecimiento del orden del 42.7\%; por otra parte, entre 1990 y 1997 la tasa de motorización creció desde 0.39 a 0.75 vehículos por habitante en esta Región, con lo cual el porcentaje de hogares sin automóvil descendió desde $70.2 \%$ a $56.5 \%$ en el mismo lapso (CONAMA, 1999). Esta situación ha generado una demanda creciente por infraestructura, todavía bastante precaria en el caso de Santiago; sin embargo, aún con esta limitación, las vías y carreteras y, en especial, las autopistas existentes se han ido afirmando como los ejes que guían la expansión suburbana, acentuando una morfología metropolitana de tipo tentacular.

Por otra parte, la adopción generalizada de las nuevas tecnologías de la información y la comunicación permitió reducir la gravitación de la distancia como factor limitante para la localización de las empresas y las familias, con lo que favoreció los emplazamientos productivos y residenciales en el periurbano. En el mismo sentido, la televisión, con una explosiva difusión hacia todos los sectores sociales, ha tendido a favorecer un mayor afincamiento cotidiano en hogares situados a distancias relativamente mayores que las que prevalecían en la ciudad más concentrada del pasado. El suministro de televisión por cable y satelital, asegurado en buena parte de los nuevos proyectos inmobiliarios periféricos para residencia de sectores de ingresos altos y medios, también contribuye al éxito de estos nuevos emprendimientos.

Todo esto indica que, la imbricación de este conjunto de factores ha estimulado una modalidad de expansión urbana que no puede considerarse como un fenómeno enteramente nuevo, sino como la lógica y previsible culminación de una forma de urbanización capitalista, que ya había comenzado a perfilarse en la época de la industrialización sustitutiva. En efecto, lo que la desregulación ha estimulado y hecho posible es una forma de metropolización expandida o ampliada, de morfología policéntrica, tipo archipiélago, en la que un importante conjunto de procesos productivos, en especial los más tradicionales, así como también la población, ya no requiere concentrarse en un área compacta, aún cuando sigue aspirando a una razonable proximidad entre si y al lugar donde se encuentran las mayores economías de aglomeración.

\section{Mercado Metropolitano de Trabajo, Pobreza y Segregación Social}

¿Qué efectos tuvo el sostenido proceso de crecimiento vivido entre 1985 y 1998 sobre la situación y la estructura social del AMS? Seguramente la principal consecuencia de este proceso, complementado por las políticas sociales aplicadas desde 1990, fue un importante aumento, tanto 
del ingreso real, como del ingreso per cápita de los hogares, al mismo tiempo que un crecimiento real tanto en el gasto de los hogares como en el gasto por persona, lo que contribuye a explicar la ya referida reactivación del mercado interno. A este respecto, los resultados de la V Encuesta de Presupuestos Familiares realizada por el INE en el Gran Santiago, en 1998, indican, con respecto a 1988, un crecimiento real de $87.5 \%$ en el ingreso mensual por hogar, de $100 \%$ en el ingreso mensual per cápita por hogar, de $84.2 \%$ en el gasto mensual por hogar y de $94.9 \%$ en el gasto mensual per cápita.

Además, también se verificó una disminución en el grado de desigualdad de la distribución del ingreso y del gasto de los hogares (INE,1999), pues mientras el 20\% de los hogares más pobres incrementaron en términos reales su ingreso per cápita desde $4.8 \%$ a $6.3 \%$, el quintil correspondiente a los sectores de mayores ingresos disminuyó su participación de un $56.1 \%$ a un $50.4 \%$ entre 1988 y 1997 (Cuadro 7). La información sobre el gasto por hogar muestra una evolución en la misma dirección, pues mientras la variación en el mismo período para el primer quintil fue de $111 \%$, la correspondiente al quinto quintil fue de solamente $68 \%$.

En este escenario, de igual forma a como ocurrió escala nacional, los niveles de pobreza y de indigencia disminuyeron significativamente entre 1990 y 1998: la pobreza se redujo desde un $33 \%$ a un $15.4 \%$ de la población de la RMS, en tanto que la indigencia descendió desde $9.6 \%$ a 3.5\% (Mideplan, 1999). Al comparar la situación de esta región con la de las restantes, se comprueba que ella es una de las que presenta menores niveles de pobreza y de indigencia, dado que solamente

\section{CUADRO 7}

Distribución del Ingreso y del Gasto de Hogares según Quintiles de Ingreso Per Cápita Gran Santiago - 1987-1997

\begin{tabular}{lccccc}
\hline \multirow{2}{*}{ Quintiles } & \multicolumn{2}{c}{ En \% } \\
\cline { 2 - 3 } & \multicolumn{2}{c}{ Distribución del Ingreso } & & \multicolumn{2}{c}{ Distribución del Gasto } \\
\cline { 2 - 3 } \cline { 5 - 6 } Todos & $1987-1988$ & $1996-1997$ & & $1987-1988$ & $1996-1997$ \\
1 & 4,8 & 100,0 & & 100,0 & 100,0 \\
2 & 8,6 & 10,0 & & 10,9 & 12,4 \\
3 & 11,9 & 13,6 & & 13,7 & 14,8 \\
4 & 18,6 & 19,6 & & 19,6 & 20,0 \\
5 & 56,1 & 50,4 & & 48,2 & 44,0 \\
\hline Fuente: INE (1999). & & & & &
\end{tabular}

las regiones II y XII tienen indicadores más satisfactorios, en tanto varias de las otras regiones duplican, o casi duplican, dichos porcentajes. Por otra parte, si se analiza la tasa de la reducción de la pobreza y de la indigencia para el período 1987-1996 según datos de la Encuesta de Caracterización Socio-Económica (CASEN), se observa que para ambos indicadores la mayor reducción corresponde a la RMS, con tasas de $-10.2 \%$ y $-16.4 \%$ respectivamente (MIDEPLAN, 1998).

Todo ello pone en evidencia que la RMS -donde la presencia del AMS es absolutamente predominante- ha sido una de las más favorecidas por el crecimiento de estos años y que los indicadores considerados muestran que $l a$ tendencia dominante ha sido hacia una disminución de la polarización social. Por otra parte, estos indicadores permiten afirmar que, en este caso, por ahora no se estaría en presencia de una tendencia hacia una mayor segmentación del mercado de trabajo y que la hipótesis de que la clase media estaría siendo perjudicada por este proceso no sería válida para el país en su conjunto ni, en particular, para el AMS.

Ello no obstante, en la medida que todavía se mantiene la regresiva distribución del ingreso a la que ya hemos hecho referencia, esto tiene su correspondiente expresión en la estructura territorial metropolitana. Pese a que en la RMS los índices promedio de pobreza en general son menores que los de otras regiones $-14.8 \%$ en 1996 , frente, por ejemplo, a $36.5 \%, 33.9 \%$ y $32.5 \%$, respectivamente, para las regiones IX (Araucanía), VIII (Bio Bio) y VII (Maule)- en términos absolutos, el número de pobres en esta parte del territorio sigue siendo el más elevado del país: 836 mil pobres y 150 mil indigentes en 1996. A ello hay que agregar que al comparar la distribución del ingreso para las distintas regiones (Cuadro 8), se puede comprobar que la polarización entre el $20 \%$ de la población de mayores ingresos y el $20 \%$ de la de menores ingresos al interior de cada una de las mismas, la de la RMS es una de las más altas del país, siendo superada solamente por las regiones de Atacama y del Bio Bio.

Esta situación de polarización social se materializa en un mapa de segregación urbana del AMS, donde es posible identificar la existencia de verdaderos "ghettos" urbanos, tanto para ricos como, especialmente, para pobres. Este mapa se hizo más nítido a raíz de las erradicaciones llevadas a cabo por el Gobierno Militar, por medio de las cuales se trasladó a la población pobre que se había asentado en el seno de barrios de ingresos altos y medios, hacia lugares homogéneamente pobres (Dockendorff, 


\begin{tabular}{|c|c|c|c|c|c|c|}
\hline \multicolumn{7}{|c|}{$\begin{array}{c}\text { Distribución del Ingreso Monetario Promedio Mensual de Hogares } \\
\text { \% del Ingreso Total Regional por Quintiles } \\
\text { Chile }-1996\end{array}$} \\
\hline & & & & & & En \% \\
\hline \multirow{2}{*}{ Region } & \multicolumn{5}{|c|}{ Quintiles } & \multirow{2}{*}{$\begin{array}{l}20 \% \text { más rico/ } \\
20 \% \text { más pobre }\end{array}$} \\
\hline & I & $\|$ & III & IV & V & \\
\hline Tarapacá & 4,8 & 9,6 & 14,9 & 21,5 & 49,2 & 10,3 \\
\hline Antofagasta & 5,3 & 10,5 & 15,5 & 21,7 & 47.0 & 8,9 \\
\hline Atacama & 4,1 & 8,0 & 11,6 & 17,6 & 58,8 & 14,3 \\
\hline Coquimbo & 5,1 & 9,9 & 13,3 & 18,4 & 53,3 & 10,5 \\
\hline Valparaíso & 5,4 & 10,3 & 13,4 & 21,8 & 49,1 & 9,1 \\
\hline O'Higgins & 4,8 & 9,6 & 13,5 & 18,9 & 53,2 & 11,1 \\
\hline Maule & 4,7 & 9,0 & 13,3 & 17,9 & 55,1 & 11,7 \\
\hline Bío Bío & 4,2 & 8,1 & 11,8 & 18.5 & 57.5 & 13,6 \\
\hline Araucanía & 4,4 & 8,9 & 13,2 & 18,5 & 55,0 & 12,5 \\
\hline Los Lagos & 5,0 & 8,5 & 12,9 & 17,7 & 55,8 & 11,2 \\
\hline Aisén & 5,3 & 9,8 & 14,8 & 20,9 & 49,2 & 9,3 \\
\hline Magallanes & 5,4 & 10,3 & 14,0 & 20,5 & 49,8 & 9,2 \\
\hline Metropolitana & 4,3 & 8,0 & 11,6 & 18,8 & 57,3 & 13,3 \\
\hline
\end{tabular}

Fuente: Elaboración propia, MIDEPLAN, Encuesta CASEN 1996.

Rodríguez y Winchester, 2000). De esta manera, según datos de la Encuesta CASEN para 1996 (MIDEPLAN, 1998), mientras en las tres comunas más ricas del AMS, Providencia, Las Condes y Vitacura, los niveles de pobreza alcanzan respectivamente al $0.8 \%, 1.1 \%$ y $1.2 \%$ de la población, en las tres comunas más pobres, Huechuraba, Renca y Pedro Aguirre Cerda, los niveles son de $38.4 \%$, $37.1 \%$ y $32.7 \%$.

La política de vivienda social también ha contribuido a la persistencia de este cuadro de segregación social dado que, como ya hemos señalado, el imperativo de bajar costos por parte de las empresas privadas que tienen a su cargo la construcción de las mismas hace que, por lo general, los sectores de menores ingresos solamente puedan acceder a viviendas de baja calidad ubicadas en terrenos de menor valor, en barrios pobres situados en áreas periféricas del AMS. De tal forma, pese a los progresos realizados, todavía subsiste un cuadro general, donde los pobres continúan teniendo una importante presencia en el noticiero cotidiano de la vida metropolitana. ${ }^{12}$

La persistencia del cuadro de polarización y segregación social esbozado, en el que durante los últimos años se ha impuesto la percepción social de un incremento de la delincuencia y la conflictividad (PNUD, 1998), que comienza a tener una creciente influencia en la vida urbana en general y, en consecuencia, en la estructura y en la apariencia de la metrópoli.

\section{Nuevos Artefactos Urbanos y Estructuración Metropolitana}

El tercer aspecto que interesa tener presente como expresión de lo nuevo, con relación a la metrópoli preexistente, apunta a un conjunto de hechos o intervenciones urbanas que denominaremos genéricamente como artefactos de la globalización, no porque su génesis pueda ser atribuida estrictamente a esta nueva fase del desarrollo capitalista, sino porque su irrupción en Chile puede explicarse por las condiciones que generaron las transformaciones producidas bajo el avance del proceso combinado de la reestructuración y la globalización. No hay duda acerca de que la mayor parte de estos artefactos ya tenían un desarrollo relevante en el período de apogeo fordista, especialmente en buena parte de las ciudades norteamericanas -aún cuando también en varias metrópolis latinoamericanas, como Sao Paulo y Bogotá-incluso con la mayor parte de los elementos y atributos que caracterizan su configuración actual, como es el caso, por ejemplo, de los denominados "shopping malls".

Sin embargo, en el caso chileno, estos artefactos surgieron bajo el alero de la reestructuración y proliferaron a medida que este proceso se intensificó, por lo que su irrupción y desarrollo en este ámbito geográfico puede ser asociado a las condiciones que ofrecieron los avances de la globalización. Varios factores permiten explicar su difusión en el escenario urbano chileno: primero, la profundización de la inserción en la dinámica global, que ocasionó fundamentales transformaciones en la modernización y diversificación tanto del aparato productivo, como de las pautas y oportunidades de consumo; segundo, el importante aumento de los ingresos familiares y personales logrados con el mayor crecimiento, lo que impulsó una sostenida recuperación del mercado interno y estimuló la aceptación generalizada de las nuevas pautas de consumo; y, tercero, la oportunidad de ampliar y diversificar los negocios inmobiliarios a través de las inversiones en nuevas configuraciones edilicias, que se presentaban como de alta rentabilidad.

De esta manera, a partir del momento en que comenzaron a proliferar en el AMS, estos artefactos pasaron a constituirse en hitos urbanos relevantes y a jugar un papel fundamental en la estructuración de la metrópoli emergente y en la revalorización de su imagen, $v i s-a-v i s$ las otras metrópolis en competencia en el ámbito de la red global de ciudades; desde entonces, muchos de ellos, se han ubicado como los símbolos más difundidos de esta 
nueva fase de modernización, esto es, en lo que Gorelik (1997:8), haciendo referencia al caso de Buenos Aires, describe como "imágenes urbanas novedosas" o "postales de la modernización". En el caso del AMS, en especial, cabría hacer referencia a:

Núcleos de actividades empresariales - entre los que se destacan los conjuntos edilicios destinados a actividades industriales y terciarias, muchos de los cuales inciden en la aparición de nuevas polarizaciones urbanas, como los grandes megaproyectos inmobiliarios con funciones combinadas y los centros empresariales especializados, algunos de ellos destinados a funciones de "back office", por lo que pasan a competir con los tradicionales distritos centrales de negocios. ${ }^{13}$ Es el caso, por ejemplo, de la Ciudad Empresarial ubicada en la zona norte de Santiago, que contempla una inversión cercana a los US \$900 millones, en más de 100 edificios y cerca de 6 kilómetros de vialidad interna de alta calidad, la cual, en agosto de 1998, del total de 40 hectáreas en oferta, ya había escriturado el $35 \%$ de los terrenos y tenía 14 edificios terminados (El Diario, 6 agosto 1998).

También pueden mencionarse los parques o centros industriales, principalmente en las coronas periféricas del AMS, de los que, hacia mediados de 1998, estaban en promoción inmobiliaria un total de 34 , de diverso tamaño y tipo de equipamiento, de los cuales siete se encontraban en etapa de proyecto de desarrollo (El Diario, 20 agosto 1998). A ellos, cabría agregar los grandes edificios corporativos inteligentes, que al tiempo que inciden en una mayor verticalización de ciertas partes de la ciudad, pasan a constituirse en verdaderos prototipos del nuevo paisaje urbano, como es el caso, por ejemplo, del World Trade Center, del Edificio de la Industria, del Edificio de Telefónica de Chile y del Boulevard Kennedy.

Centros comerciales diversificados y/o especializados - Impuestos por la evolución de las prácticas comerciales que cobran mayor impulso al ritmo de la globalización, como los "shopping malls". Concebidos como verdaderos sub-centros urbanos ("town centers"), en torno a los que se articula la vida de determinados barrios o comunas, y que constituyen la mejor expresión de las nuevas modalidades de espacio público socialmente estratificado de propiedad privada. La propaganda realizada para uno de los más importantes de estos centros comerciales ilustra sobre el alcance de esta concepción y sobre el papel que se les asigna en la estructura urbana:
"Plaza Vespucio Town Center: el primer Centro de Gravedad de nuestro país. Plaza Vespucio se abre al exterior, generando espacio urbano en sus alrededores y nuevos usos que responden a los intereses de los habitantes de Santiago. Un nuevo concepto en Chile, Town Center: área central compacta creada para vivir, trabajar, comprar, comer, divertirse y satisfacer todas las necesidades en un solo lugar". Y de inmediato enumera las novedades que irá incorporando en los próximos años, para constituirse en un verdadero "town center": "1997, Conexión línea cinco del metro (Estación Vespucio), Centro clínico Vespucio, 1.500 estacionamientos subterráneos, ampliación del mall, gran tienda especializada. 1998, ampliación food-court, torre de oficinas, complejo multimedia, segundo complejo de cines, paseo de restoranes temáticos. 1999, complejo financiero, gimnasio y centro de salud integral. 2000, hotel, centro de eventos, convenciones y exposiciones".

A este tipo de configuración, cabría agregar la multiplicación de grandes superficies comerciales, tanto enfocadas hacia el consumo diversificado (super e hipermercados), como especializado, por ejemplos en artículos para el hogar (Home Center, Easy, Home Depot), para el automóvil (Movicenter), etc., que en muchos casos están provocando la decadencia y/o desaparición de numerosos pequeños comercios vecinales. Por otra parte, también cabría mencionar la proliferación de los llamados patios de comida, donde se impone el culto al "fast food", con amplia representación de cadenas globales de comida chatarra (McDonalds, Burger King, Pizza Hut, etc.), generalmente implantadas bajo el régimen de franquicias.

\section{Hoteles cinco estrellas y recintos para conferencias y} eventos - En este caso estamos en presencia de un tipo de artefacto en cuya multiplicación indudablemente tiene una decisiva influencia la intensificación de la inserción externa, que estimula un flujo permanente de visitantes bajo el impulso de la globalización de los negocios. Es así que, a junio de 1998, la Asociación Gremial de los Hoteleros de Chile, registraba 15 hoteles de cinco estrellas en Santiago, con 2.766 habitaciones, representando el $38 \%$ de la oferta hotelera de esta ciudad, todos ellos ubicados en cuatro comunas (Comuna de Santiago en el centro y Providencia, Las Condes y Vitacura al oriente de la ciudad) (El Mercurio, 2 agosto 1998).

Configuraciones urbanas para el esparcimiento - En este ámbito los cambios corresponden a la difusión, a escala mundial, de formas de esparcimiento asociadas a productos 
vinculados a las nuevas tecnologías, especialmente en el campo de la electrónica, como es el caso, por ejemplo, de los multiplex o complejos de salas cinematográficas, expresión de nuevas modalidades comerciales asociadas al espectáculo del cine, que están poniendo fin a la ya debilitada supervivencia de las salas cinematográficas tradicionales. Es así que, en 1998, los tres principales operadores multinacionales de multiplex en Chile incorporaron 99 nuevas salas de este tipo, de las cuales 68 en la RMS, cinco en otras ciudades de la región central y siete en el resto del país. (El Mercurio, 2 agosto 1998). A ello habría que agregar los nuevos tipos de salas de máquinas electrónicas, todavía de escasa relevancia en el AMS y la aparición de los parques temáticos de esparcimiento, según una modalidad impuesta por los complejos tipo disneylandia, como es el caso de la concepción establecida para el nuevo zoológico de La Pintana en Santiago.

Edificios y conjuntos residenciales protegidos y segregados - Aparecen como resultado de los intentos de los operadores inmobiliarios por dar respuesta a los nuevos requerimientos derivados de las ya aludidas estrategias individuales o familiares, donde se destaca un significativo aumento de la oferta de departamentos, orientada principalmente hacia sectores de ingresos medios y altos, concentrada fuertemente en las comunas de Providencia, Las Condes, Vitacura, Ñuñoa y Santiago, cuya multiplicación también ha contribuido a la mayor verticalización de partes importantes de la ciudad.

Al mismo tiempo, nuevos barrios y condominios cerrados y protegidos se esparcen en forma incontrolable hacia el sur y el norte del AMS, a lo que además cabría agregar la expansión hacia la zona costera, favorecida por la mejor accesibilidad desde Santiago, lograda con la terminación de la Autopista del Sol, a través de una sucesión de nuevas urbanizaciones entre Santo Domingo al sur y Concón al norte, que se han multiplicado durante los últimos años. En la misma dirección, también se ha observado que algunos segmentos de los sectores de altos ingresos, frente a ciertos problemas que afectan en mayor grado a la vivienda individual (por ejemplo, cambios en la composición familiar, aumento de la delincuencia, etc.), han optado por residir en departamentos de alto estándar y gran superficie, ubicados en barrios elegantes de partes exclusivas de la ciudad (ciertos sectores de El Golf, San Damián, Vitacura).

Este variado conjunto de artefactos, en la medida que se sitúan como las intervenciones urbanas más destaca- das de los nuevos tiempos, inducen significativas transformaciones en la configuración de la metrópoli emergente y en la correspondiente vida urbana, por lo general con gran impacto en los lugares en que se implantan. De esta manera han valorizado nuevas áreas y han contribuido a la reestructuración de partes enteras del AMS, al tiempo que han incidido en la caracterización de la nueva imagen metropolitana. En este sentido, juegan un papel fundamental en el marketing de Santiago en la competencia interurbana latinoamericana.

\section{ENTRE EL COLAPSO Y LA NOSTALGIA}

El análisis precedente permite concluir que los procesos de reestructuración y globalización han provocado un importante conjunto de cambios en la estructura y el funcionamiento del AMS, que se han manifestado principalmente en:

- una acentuación de la tendencia a la suburbanización, haciendo que la mancha metropolitana continúe con un proceso expansivo que no parece encontrar límites;

- la persistencia de una estructura social metropolitana polarizada y segregada, en la que se ha acentuado la tendencia a que los pobres vivan junto a los pobres y los ricos junto a los ricos $\mathrm{y}$;

- una morfología metropolitana que está siendo fuertemente impactada por la irrupción de un conjunto de nuevos artefactos urbanos.

En lo fundamental, este conjunto de transformaciones puede interpretarse como la culminación de ciertas tendencias y fenómenos inherentes al proceso de construcción urbana capitalista, que ya se habían esbozado nítidamente en el pasado. En otras palabras, el conjunto de cambios producidos en este período no implica una ruptura fundamental con la ciudad heredada y parece perfectamente funcional a la afirmación de un tipo de configuración metropolitana, cuyos cimientos habían sido establecidos en el período de auge del modelo de crecimiento hacia adentro. De hecho, desde que la liberalización y desregulación lograron remover los obstáculos con los que las políticas urbanas de inspiración keynesiana habían intentado frenar la expansión metropolitana, la mancha urbana ha podido expandirse con mucho mayor libertad. Bajo esta dinámica, el modelo de ciudad de corte europeo, que ayer se había constituido en el principal referente de buena parte de las ciudades latinoamericanas y en particular de Santiago, hoy deja paso 
a otro, del que Los Angeles parece suministrar el modelo más acabado.

Frente a los problemas que se han venido incubando en el seno del AMS, en los últimos años se han multiplicado las opiniones de que esta aglomeración estaría al borde del colapso, por lo que sería necesario tomar medidas para detener su crecimiento, buscando, al mismo tiempo, estimular el mayor crecimiento de otras regiones y ciudades e, incluso, eventualmente, comenzar a pensar en el traslado de la capital. Muchas de estas propuestas suelen responder a visiones nostálgicas de la ciudad del pasado, ahora idealizada en función de ciertas supuestas virtudes que, en general, no fueron igualmente valoradas en su momento. En otros casos, alienta el alegato de los regionalistas y de las comunidades regionales, clamando por una distribución territorial más equitativa de los frutos del crecimiento, en un discurso que tiende a soslayar el papel que, en el contexto de la dinámica económica globalizada, Santiago cumple con respecto al crecimiento de la nación en su conjunto.

Por lo general, en estos alegatos y discursos, se elude considerar los factores que condicionan y estimulan la acumulación y el crecimiento en esta nueva etapa del desarrollo capitalista y, en particular, a los que condicionan las decisiones de las empresas sobre su localización que, en definitiva, son el verdadero motor que sustenta este tipo de expansión metropolitana. En muchos casos, en los discursos aludidos parece estar subyacente la idea de que la concentración de empresas en el AMS, más que a una lógica económica capitalista, respondería a arbitrarios caprichos empresariales. Es este tipo de razonamiento el que permite suponer la pertinencia de propuestas utópicas que, en última instancia, sólo serían posibles bajo otra lógica económica, de naturaleza y viabilidad desconocida.

Más allá de los múltiples problemas que afectan al AMS, como a la mayoría de las grandes metrópolis en expansión, parece importante reiterar que lo que se logró con la aplicación de políticas de liberalización económica y de desregulación fue despejar el camino para la afirmación de una lógica estrictamente capitalista en la producción y la reproducción metropolitana. Lo que permitió llevar a su culminación ciertas tendencias que ya estaban presentes, quizás en forma más tenue, en la ciudad que se había configurado bajo el impulso de la industrialización sustitutiva. Por lo tanto, como se ha tratado de mostrar en estas páginas, lo que aparece como nuevo, aún cuando significa cambios importantes en la metrópoli heredada, en lo esencial, refuerza y profundiza tendencias preexistentes y, con ello, asegura que lo que existía siga existiendo.

\section{NOTAS}

Versión revisada y actualizada del artículo publicado en la Revista Eure, Santiago de Chile, v. XXV, n.76, diciembre 1979 (revisión enero 2000). El autor agradece la colaboración de Luis Riffo Pérez en la elaboración y análisis de algunos de los cuadros incluidos.

1. El AMS forma parte de la Región Metropolitana de Santiago (RMS), que es una de las 13 regiones en que está dividido administrativamente el territorio chileno. La RMS está dividida en 5 provincias y en 51 comunas. La Provincia de Santiago, está dividida en 32 comunas, las que conjuntamente con las Comunas de Puente Alto (Provincia de Cordillera) y de San Bernardo (Provincia de Maipo) conforman actualmente el AMS.

2. El análisis de este trabajo está referido básicamente al período 1985-1998 que se caracteriza por un elevado y sostenido crecimiento económico, por lo que muchas de sus conclusiones pueden carecer de validez para los años siguientes, cuando la economía chilena fue seriamente afectada por la crisis asiática, produciéndose una fuerte caída de la tasa de crecimiento y un significativo aumento del desempleo.

3. En este sentido, Contreras (1998:315) destaca que "varias investigaciones muestran que la distribución de los ingresos en Chile es una de las más desiguales del mundo, pero que dicha desigualdad se ha mantenido relativamente estable desde una perspectiva de largo plazo." Con respecto a la estabilidad en el tiempo de la distribución del ingreso, es importante tener en cuenta que "la conclusión de que existe una distribución estable del ingreso a través del tiempo coincide con evidencia de otros países. En un reciente informe que analiza las mediciones de la desigualdad en 108 países, se concluyó que, a pesar de que entre los países hay diferencias sustanciales en cuanto a desigualdad, los cambios distributivos a lo largo del tiempo en cualquier país son muy leves." (Valdés, 1999:10-11).

4. Utilizamos el concepto de atractividad en forma equivalente al de fertilidad aplicado por Kamppeter (1995) a los ámbitos regionales o nacionales percibidos por las empresas como más favorables para que sus capitales puedan germinar mejor, en función de la existencia de un conjunto de factores que aseguran una mayor productividad e ingreso.

5. En una Encuesta sobre Factores de Localización Industrial, realizada en 1996 entre establecimientos de los seis sectores (a cuatro dígitos CIUU) de mayor dinamismo, ubicados en las seis regiones más industrializadas de Chile, uno de los factores destacados para explicar la preferencia por la RMS, fue la mayor disponibilidad de profesionales y gerentes de esta Región (de Mattos, Riffo y Reyes, 2000).

6. Como señala Saskia Sassen, "la combinación de la dispersión geográfica de las actividades económicas y la integración de sistemas que constituyen la base de la era económica actual ha contribuido a la creación o ampliación de funciones centrales, en tanto que la complejidad de las operaciones ha llevado a un aumento de la demanda de servicios sumamente especializados" (Sassen, 1997:2).

7. Para una metrópoli de la periferia capitalista, como es el caso de Santiago, antes que de ciudad global, parece más apropiado hablar de ciudad en proceso de globalización ("globalizing city") como proponen Marcuse y van Kempen (2000).

8. En este sentido parece pertinente la afirmación de Marcial Echenique en el sentido de que "Santiago tiene el $40 \%$ de la población del país, el $50 \%$ de su industria, el $75 \%$ de los servicios importantes que generan riqueza ... ¿se puede detener todo eso? Si Santiago se paraliza, las inversiones extranjeras que llegan no se irían a Valparaíso o a Concepción. Se irían a Buenos Aires o Sao Paulo. A ciudades más eficientes" (La Tercera, 30/agosto/1998).

9. A este respecto, el Ministro de la Vivienda y Urbanismo (MINVU), afirmó que "el objetivo de la tarea del MINVU [...] es que estas nuevas personas [los 3 millones de habitantes que se irán incorporando al AMS en el futuro] no se localicen en Santiago, sino que vayan a otra futuras áreas de desarrollo urbano, como Talagante, Melipilla, Cordillera o Maipo, en un escenario de posibles nuevas ciudades donde muchas están todavía por determinar" (El Mercurio, 14 agosto 1998).

10. En esta situación, por ejemplo, ha proliferado la actitud de tratar de aprovechar al máximo la superficie construida permitida por las regulaciones sobre alturas y rasantes, dando lugar a unos edificios cuasi piramidales, que semejan las cajas de los lustradores de zapatos (por lo que popularmente se los denomina como edificios "lustrines"), o a otros en los que, dadas las restricciones impuestas por las 
ordenanzas sobre altura máxima, se hunde el primer piso para aumentar la utilización del terreno, todo lo cual redunda en una horrenda estética urbana.

11. Entendida, como una operación inmobiliaria de renovación urbana enfocada hacia áreas centrales antiguas, por la que se busca reemplazar a sus moradores de bajos recursos por otros de mayores ingresos.

12. Una crónica sobre un incidente conocido como el "saqueo a la bodega incendiada" brinda un ejemplo elocuente a este respecto: "[...] cientos de personas están pernoctando y pasando todo el día en las afueras de una bodega comercial incendiada la semana pasada en Quilicura, esperando entrar para saquear lo poco que queda. 'Al dueño la mercadería no le sirve de nada. A nosotros sí, porque somos pobres', dice uno de ellos. 'Pero este es un recinto privado', le dice el periodista. 'Sí, pero nosotros somos pobres y ellos van a botar estas cosas que a nosotros nos sirven', replican varios con una lógica tan implacable como inútil. Las rejas no se abren, el saqueo es contenido por policías y guardias" (La Hora, 6 octubre 1998).

13. Corresponde a una tendencia mundial, donde se destacan ejemplos como La Defense (Paris), Canary Wharf/Isle of Dogs (Londres), Puerto Madero (Buenos Aires) o Santa Fe (Ciudad de México).

\section{BIBLIOGRAFÍA}

AGLIETTA, M. Regulación y crisis del capitalismo. Madrid, Siglo XXI de España Editores, 1979.

BAILLY, A.S. y COFFEY, W.J. "Localisation des services a la production et restructurations économiques”. L'Espace Géographique. Paris, n.1, 1994.

CEPAL. La inversión extranjera en América Latina y el Caribe. Naciones Unidas, Santiago, 1997.

CIDU - EQUIPO MACROZONA CENTRAL. "Síntesis del Estudio 'Región Central de Chile': perspectivas de desarrollo". Revista Eure. Santiago, n.6, noviembre 1972 .

CONAMA (Comisión Nacional del Medio Ambiente). La calidad del aire de Santiago está mejorando. Santiago, abril 1999.

CONTRERAS, D. "Distribución del ingreso en Chile. Nueve hechos y algunos mitos". Perspectivas. Santiago, v. 2, n.2, 1998.

COWAN, K. y DE GREGORIO, J. "Distribución y pobreza en Chile: ¿estamos mal? ¿ha habido progresos? ¿hemos retrocedido?”. Estudios Públicos, n.64, primavera 1996.

DAHER, A. "Gestión urbana: un desafío estratégico". En: PGU (PROGRAMA DE GESTIÓN URBANA). Chile urbano. Antecedentes de la consulta nacional para la formulación de una nueva política de desarrollo urbano 19931996. Quito, Ecuador, 1996.

DE CASTRO, S. (Ed.) El Ladrillo. Bases de la politica económica del Gobierno Militar chileno. Santiago, Centro de Estudios Públicos, 1992.

DE MATTOS, C.A. "Reestructuración, globalización, nuevo poder económico y territorio en el Chile de los noventa". Revista de Estudios Regionales. Málaga, n. 43 , septiembre-diciembre 1995 .

"Avances de la globalización y nueva dinámica metropolitana: Santiago de Chile, 1975-1995”. Revista Eure. Santiago, n.65, junio 1996.

DE MATTOS, C.A.; RIFFO PEREZ, L. y REYES, S. "Reestructuración, crecimiento y concentración territorial de la industria: el caso de la Región Metropolitana de Santiago". Santiago Metropolitano, CD-Rom. Santiago, PISM/PUC/SUR, enero 2001.

DOCKENDORFF, E.; RODRIGUEZ, A. y WINCHESTER, L. "Santiago de Chile: metropolization, globalization and inequity". Environnment \& Urbanization, v. 12 , n.1, abril 2000 .
DUCCI, M.E “Chile: el lado oscuro de una política de vivienda exitosa”. Revista Eure. Santiago, n.69, julio 1997.

ENCLA. Encuesta Laboral 1998. Informe Ejecutivo. Ministerio del Trabajo. Departamento de Estudios. Santiago, 1998.

GEISSE, G. Economía y politica de la concentración urbana en Chile. México, El Colegio de México/PISPAL, 1983.

GONZALEZ, S.; HALES, P. y OYOLA, J. "Santiago, una ciudad trizada". En: COLEGIO DE ARQUITECTOS DE CHILE. Hacer ciudad. Santiago, Ediciones AUCA, 1979

GORELIK, A. "Buenos Aires en la encrucijada: modernización y política urbana". Punto de Vista. Buenos Aires, n.59, diciembre 1997.

HURTADO RUIZ-TAGLE, C. Concentración de población y desarrollo económico. El caso chileno. Santiago, Universidad de Chile, Instituto de Economía, 1966.

INE (Instituto Nacional de Estadísticas). Compendio Estadístico 1998. Santiago, 1998.

. V Encuesta de Presupuestos Familiares 1996-1997. Serie Estadísticas Sociales $N^{o} 1$. Santiago, junio 1999.

KAMPPETER, W. "Fertilidad nacional, Estado-nación y sistema económico mundial". Nueva Sociedad. Caracas, n.137, mayo-junio 1995.

MARCUSE, P. y VAN KEMPEN, R. Globalizing Cities. A New Spatial Order? Blackwell, Oxford, UK, 2000

MASSONE MEZZANO, C. "Decreto 420. Planificación urbana 1979/1990". CA - Ciudad Arquitectura. Santiago, n.81, julio-setiembre 1995.

MIDEPLAN (Ministerio de Planificación y Cooperación). Evolución de la pobreza e indigencia en Chile, 1987-1996. Santiago, División Social, enero 1998.

Pobreza y distribución del ingreso en Chile, 1990-1998. Santiago, División Social, julio 1999.

MINVU "Política Nacional de Desarrollo Urbano. Chile, 1979". Revista Eure. Santiago, n.22, setiembre 1981 .

MIRANDA MUÑOZ, C.A. "Expansión urbana intercensal del Gran Santiago 18751992". Estadística y Economía. Santiago, segundo semestre 1997.

PNUD. Desarrollo Humano en Chile. Las paradojas de la modernización. Santiago de Chile, marzo 1998.

Informe sobre Desarrollo Humano 1999. Madrid, PNUD/Ediciones Mundi-Prensa, 1999.

Informe sobre Desarrollo Humano 2000. Madrid, PNUD/Ediciones Mundi-Prensa, 2000.

OIT (Organización Internacional del Trabajo). Chile. Crecimiento, empleo y desafio de la justicia social. Santiago, 1998.

REICH, R.B. The Work of Nations. New York, Vintage Books, 1992.

RODRIGUEZ VIGNOLI, J. "La población del Gran Santiago: tendencias, perspectivas y consecuencias". Celade, agosto 1993.

ROMERO, H. y TOLEDO, X. "Crecimiento económico, regionalización y comportamiento espacial del sector inmobiliario en Chile". Terra Australis. Santiago, n.43, 1998.

RIFFO PEREZ, L. y SILVA, V. "Las tendencias locacionales de la industria en el marco de los procesos de reestructuración y globalización en Chile". Estadística y Economía. Santiago, n.11, diciembre 1995.

SASSEN, S. "Ciudades en la economía global: enfoques teóricos y metodológicos". Revista Eure. Santiago, n.71, marzo 1998.

SMITH, N. The New Urban Frontier. Centrification and the Revanchist City. Londres, Routledge 1996.

VALDES, A. "Pobreza y distribución del ingreso en una economía en alto crecimiento: Chile, 1987-1995”. Estudios Públicos. Santiago, n.75, invierno 1999. 